\title{
Repeated failures in reducing rat's spontaneous alternation through the intertrial disruption of spatial orientation*
}

\author{
PAUL M. BRONSTEIN†, TERRY DWORKIN, BENJAMIN H. BILDER, and F. DMITRI WOLKOFF \\ Brooklyn College of the City University of New York, Brooklyn, New York 11210
}

\begin{abstract}
Three experiments examined the contention that an extramaze cue representing relative spatial direction controls rats' spontaneous alternation. Attempts to eliminate this short-term directional memory by horizontally rotating the Ss were without effect. These data, along with other recent findings, cast doubt upon the completeness of Douglas's model of spontaneous alternation.
\end{abstract}

Spontaneous alternation, the tendency to enter opposing arms of a T-maze on successive turns, has been reported in rats for more than half a century (cf. Fowler, 1965). One of the more elaborate, successful, and perhaps the most widely cited of the recent studies of alternation was conducted by Douglas (1966a). In these experiments, alternation was attributed to only two cues. First, there was the relatively weak tendency for an animal to avoid its own odor trail. Second, the rats displayed a strong inclination to use extramaze spatial cues when encountering a $T$-maze choice point on successive occasions. Furthermore, these two factors were shown to combine additively.

The same investigations showed that spatial information would be eliminated and alternation would not exceed chance levels if the rats were shaken horizontally between maze-arm choices. Since vertical tilting of the rats was without significant effect, while middle ear disease was disruptive (Douglas, 1966b), a "vestibular" memory system was postulated as the mechanism mediating alternation in response to extramaze spatial cues.

In order to document further the importance of rats' spatial memories in spontaneous alternation, three attempts were made to disrupt the behavior through the horizontal turning of Ss between choices.

\section{EXPERIMENT I}

\section{Method}

Subjects and Apparatus. The Ss were 37 male and female Sprague-Dawley albino rats born in the Brooklyn College colony; these animals were 48 days old at the start of the procedure and had previously experienced both handling and maze adaptation trials (without any food or water reinforcement). Except for an occasional individually housed $\mathrm{S}$, these rats were placed two to a cage (same-sex pairs) on a schedule of ad lib Purina Lab Chow

\footnotetext{
*This research was supported by Grant 1442 from the Research Foundation of the City University of New York and by Grant MH 22027-01 from the National Institute of Mental Health. We wish to thank Judi Gardner, Stephen M. Hirsch, and Rene Stolove for their technical assistance.

TReprints: Paul M. Bronstein, Department of Psychology, Brooklyn College of the City University of New York, Brooklyn,
} New York 11210. and water. The colony was brightly illuminated $18 \mathrm{~h} /$ day $(8 \mathrm{a} . \mathrm{m}$. to 2 a.m.), with ambient temperature fluctuating at about $74^{\circ} \mathrm{F}$.

One bottomless plywood T-maze (painted flat black) was the apparatus for all studies. The maze was $10.48 \mathrm{~cm}$ wide with a clear Plexiglas top. Three tuillotine doors of white plastic divided the maze into startbox and runway (each $20.32 \mathrm{~cm}$ long) and goal arms (each $28.35 \mathrm{~cm}$ long). The T-maze was $6.4 \mathrm{~cm}$ high, placed on a black wooden table, and illuminated by a $15-\mathrm{W}$ incandescent bulb shaded upward and placed approximately $0.75 \mathrm{~m}$ above the choice point. In order to mask odor cues, the table beneath the maze was wiped with dilute acetic acid (2\%-3\%) following each turn.

Procedure. Twenty days of testing, four 5-day weeks, were employed, and each $\mathrm{S}$ was given the opportunity to make two turns of running each day. Week 1 was followed by 9 days without testing, after which the remaining 15 days of alternation trials were applied consecutively. Ss were carried to the running room individually, placed into the startbox facing the door, and, after approximately $5 \mathrm{sec}$, all guillotines were lifted. When a rat left the startbox, the door in the stem of the maze was lowered to prevent retracing, and once the $S$ had turned into an arm, it was confined there for $25 \mathrm{sec}$. Turns were defined as movements sufficiently far into an arm to permit the closing of the choice point doors while touching only the animal's tail. A trial was stopped whenever an $S$ failed either to leave the startbox within $60 \mathrm{sec}$ or to complete a turn within $3 \mathrm{~min}$. Fewer than $5 \%$ of all possible turns were eliminated because of failures to meet these criteria.

During Week 1 a second daily turn was permitted following a 20 -sec intertrial interval, during which time $S$ was confined to a small plastic bucket. Also, the animals were divided into two groups having statistically equivalent rates of alternation during the first week. These two groups then served as Ss for subsequent variations in procedure.

Group A was subjected to a period of horizontal turning between arm entries on Week 2, while vertical turning was interposed between the trials of Week 3 . Group B received the identical treatments, but in the opposite order. The horizontal and vertical manipulations were applied to the rats for a 5- to $10-\mathrm{sec}$ period following their $20 \mathrm{sec}$ in the holding cage and just prior to their being returned to the startbox. The Ss were hand held with their heads pointed away from the $E$ and their ventral surfaces roughly parallel to the floor of the chamber. They then received eight rapid movements, each of which described an arc of approximately $100 \mathrm{deg}$. In the horizontal treatment, the first movement was always to the left, while the initial deflection was always upward when the Ss were swung vertically. Finally, Week 4 was methodologically identical to Week 1 , that is, there was no intertrial turning of the rats.

\section{Results}

The computational procedures offered by Douglas 
Table 1

Percent True Alternation

\begin{tabular}{cccccc}
\hline & & \multicolumn{4}{c}{ Weeks of Testing } \\
\cline { 3 - 6 } Group & & 1 & 2 & 3 & 4 \\
\hline & & \multicolumn{4}{c}{ Experiment I } \\
A & $\mathrm{N}=18$ & 66 & 65 & 63 & 66 \\
B & $\mathrm{N}=19$ & 73 & 67 & 71 & 74 \\
& & & \multicolumn{2}{c}{ Experiment II } \\
A & $\mathrm{N}=20$ & 69 & 67 & 68 & 79 \\
B & $\mathrm{N}=20$ & 72 & 73 & 76 & 82 \\
& & & & \\
& & & & \\
$\mathrm{H}$ & $\mathrm{N}=18$ & 72 & 71 & & \\
V & $\mathrm{N}=18$ & 73 & 75 & \\
$\mathrm{C}$ & $\mathrm{N}=18$ & 72 & 73 & \\
\hline
\end{tabular}

(1966a) are followed throughout the current paper. Hence, "true" alternation refers to the percentage of spontaneous alternation realized following a correction for any turn bias that might have been seen.

A replication of Douglas's findings would be manifest in a significant decrement in alternation when the Ss were turned horizontally between $\mathrm{T}$-maze responses (i.e., Group A on Week 2 and Group B on Week 3). As depicted in the upper panel of Table 1 , no such result was obtained. Both groups displayed significant levels of alternation on each week of testing $(z \geqslant 2.23, p \leqslant .025)$, but there was no reliable difference between Groups $A$ and $B$ on any week $(z \leqslant 1.23, p \geqslant .219)$.

\section{EXPERIMENT II}

The first study was a clear failure to duplicate Douglas's (1966a) findings and calls into question, perhaps, the conclusion that a short-term "vestibular" memory is responsible for spontaneous alternation in the rat. Experiment II was a further attempt at replication, but with one procedural variation. If swinging a rat horizontally destroys the short-term storage or recall of memories for the absolute direction of recent movements, the latency between the response and the onset of the putative amnestic agent may be a crucial factor. Other treatments known to alter the short-term storage of information are time dependent (e.g., Riege \& Cherkin, 1973). It may be necessary to apply the horizontal turning immediately following an animal's removal from the maze if alternation is to be disrupted. In Experiment I a $20-\mathrm{sec}$ delay intervened between the rat's removal from the goalbox and its being manipulated by $\mathbf{E}$. The intertrial manipulations of the second study were effected just as the Ss were removed from the apparatus following the initial response.

\section{Method}

The Ss were 40 rats, half of them male, born in our laboratory and maintained identically to the animals of Experiment $I$. These rats were approximately 40 days old at the start of the procedure and had received maze and handling adaptations previously. The apparatus and procedure were identical to those of the prior study, except that the turning of the rats between trials followed the initial arm entry and confinement with as brief a delay as possible (maximum of $5 \mathrm{sec}$ ). Holding cage restraint $(20 \mathrm{sec})$ followed the intertrial shaking.

As before, four 5-day weeks of data collection were used, and 14 days without running separated Weeks 1 and 2 . There was a 5-day interval between Weeks 2 and 3, while the final 10 days of alternation testing were run consecutively. On Weeks 1 and 4 the control procedure of not shaking the animals between daily trials was used, while the turning treatments of Experiment I were employed during the 2 intervening weeks. Groups A and B each were composed of $20 \mathrm{Ss}$ showing statistically equivalent Week-1 behavior. Group A was swung horizontally on Week 2 and vertically on Week 3; for Group B the counterbalanced order obtained.

\section{Results}

As depicted in the central panel of Table 1, the independent variable had no reliable effect upon the rate of alternation. Significant levels of alternation were observed in both groups on all 4 weeks $(p<.01$ for all). No reliable difference between Groups $A$ and $B$ was apparent in any week $(z \leqslant 1.15, \mathrm{p} \geqslant .25)$.

\section{EXPERIMENT III}

Although the manipulations of the first two studies approximated the turning procedures used successfully by Douglas (1966a), our rats may have been relatively insensitive to those intertrial treatments. Therefore, in the third experiment Ss were shaken with greatly increased vigor between trials.

\section{Method}

The Ss were 54 male and female rats of the same colony stock and with the same maintenance conditions as the rats of the two prior studies. The only exception was that the animals of Experiment III were housed individually. All rats had been well handled and adapted to T-mazes; they were 106-110 days old at the start of this 2-week experiment.

Week 1 involved a format identical to the first week of Experiment II, except that 6 consecutive days of testing were used. During this initial baseline period, three groups of $18 \mathrm{Ss}$ each with statistically equivalent rates of alternation were formed. Following 6 days without any testing or handling, the Ss were exposed to 7 consecutive days of testing. It was during Week 2 that the groups were procedurally segregated.

Except for the fact that groups of animals were now transported to the running room in individual carrying cages, the basic running technique of Experiment II was followed. Rats were treated immediately after their removal from the maze following their initial daily response. The Ss of Group $\mathrm{H}$ were given eight horizontal turns, each describing a 360-deg arc: Three counterclockwise spins were followed by four clockwise movements, and then by one final counterclockwise turn. These manipulations were performed by placing an animal on a nearby table, with $\mathrm{E}$ using both hands to rotate the S. Group V animals were given four consecutive up-and-down movements in a vertical plane between trials. The Ss were initially moved upward, and the distance from the apex to the base of each oscillation was approximately $1 \mathrm{~m}$. The administration of horizontal and vertical treatments required 10-12 sec/animal, and the control Ss (Group C) were gently held by $E$ for the same time period." Following these intertrial treatments, all animals were placed in the holding cage for $20 \mathrm{sec}$, after which a second trial was run. 


\section{Results}

As documented in the lower panel of Table 1, our manipulations failed again to alter rates of alternation reliably. All groups showed highly significant levels of spontaneous alternation on both weeks ( $p<.01$ for all), while none of the intergroup comparisons was reliable on Week $2(\mathrm{z} \leqslant .61)$.

\section{GENERAL DISCUSSION}

Taken together, these studies support the conclusion that Douglas's (1966a) extensive taxonomy of the determinants of a rat's spontaneous alternation is incomplete. In spite of our persistent attempts to eliminate both odor and spatial cues, significant levels of alternation were found in all studies. There was no evidence to support the hypothesis that the horizontal turning of Ss between alternation trials has any consequence for that behavior.

No extensive analysis of the cues responsible for spontaneous alternation in this laboratory has been completed. It is clear, however, that Douglas's two-stimulus model is inadequate to account for some other recent findings. First, Dworkin and Bronstein (1974) gave 60 adult rats (four groups of 15 Ss each) 7 consecutive days of alternation trials. Turns were made in either one or two identical mazes (the same apparatus as that described earlier) with the stems parallel and Ss initially moving southward on all trials. The independent groups received two choices in the westerly maze, two trials in the easterly maze, or one turn in each (east-west and west-east orders being represented by separate groups). Animals that were transported between mazes were so moved with a minimal amount of turning by $\mathrm{E}$.

The rate of alternation for the double-maze groups was $51.3 \%(\mathrm{z}=0.36, \mathrm{p}=.72)$, while Ss making both turns in one apparatus alternated at a rate of $73.1 \%$ $(z=6.57, p<.001)$. The difference between one- and two-maze conditions was reliable $(z=2.12, p=.034)$. Due, perhaps, to the greater salience of odor trails, the single-maze groups might have been expected to display somewhat more alternation than Ss turning in two mazes. Yet, according to Douglas's model, all groups should have been alternating significantly above chance. In no group was the supposedly robust extramaze factor (relative turning direction) eliminated. ${ }^{2}$
Also contrary to Douglas's formulation is a failure to obtain above-chance alternation in a two-maze design similar to that of Dworkin and Bronstein (Sherrick \& Dember, 1966a). Hence, not only does the current paper report highly significant alternation where intertrial shaking should have eliminated the behavior but also reliable alternation is absent in other studies where extramaze spatial memories should have been available to the Ss.

There is no doubt that rats ambulate in directions which carry them away from previously chosen paths (Dember, Sherrick, \& Harris, 1966; Sherrick \& Dember, 1966a, b). Such findings support Douglas's theory; but the influence of this particular factor upon altemation is questioned by the current work. If intratrial shaking in the horizontal plane disrupts spontaneous alternation, it does so only in conjunction with other, and as yet unspecified, variables.

\section{REFERENCES}

Dember, W. N., Sherrick, M. F., \& Harris, R. P., Jr. Trial-twc goal arm alternation to orientation of trial-one starting stem. Psychonomic Science, 1966, 6, 31-32.

Douglas, R. J. Cues for spontaneous alternation. Journal of Comparative \& Physiological Psychology, 1966a, 62, 171-183.

Douglas, R. J. Spontaneous alternation and middle-ear disease. Psy chonomic Science, 1966b, 4, 243-244.

Dworkin, T., \& Bronstein, P. M. The development and control of spontaneous alternation in the rat. Paper presented at the meeting of the Eastern Psychological Association, Philadelphia, April 1974.

Fowler, H. Curiosity and exploratory behavior. New York: Macmillan, 1965.

Riege, W. H., \& Cherkin, A. Retrograde enhancement of memory in goldfish by a time-dependent temperature shift. Physiology \& Behavior, 1973, 11, 555-561.

Sherrick, M. F., \& Dember, W. N. The tendency to alternate direction of movement as reflected in starting stem running speed. Psychonomic Science, 1966a, 6, 29-30.

Sherrick, M. F., \& Dember, W. N. Trial-two goal arm alternation to direction of movement in trial-one straight alley. Psychonomic Science, 1966b, 6, 317-318.

\section{NOTES}

1. These eight $360-\mathrm{deg}$ revolutions approached the maximum amount of turning that our animals would tolerate. Pilot work showed that the rats would escape from $E$, vocalize, and usually not run for a second trial if this amount of turning was applied more rapidly, i.e., in an 8- to 10-sec period,

2. Dworkin and Bronstein (1974) also showed that the chance levels of alternation among the double-maze $S$ s were not the result of some variable associated with those particular animals. The subsequent shift of the two-maze rats to a single apparatus for both of their daily turns (with odor trails removed) resulted in their showing approximately $70 \%$ alternation.

(Received for publication April 11, 1974; accepted April 24, 1974.) 